Flach, J. M., Feufel, M. A., Reynolds, P. L., Parker, S. H., \& Kellogg, K.M.

\title{
Decisionmaking in practice: The dynamics of muddling through
}

Journal article | Accepted manuscript (Postprint)

This version is available at https://doi.org/10.14279/depositonce-7077

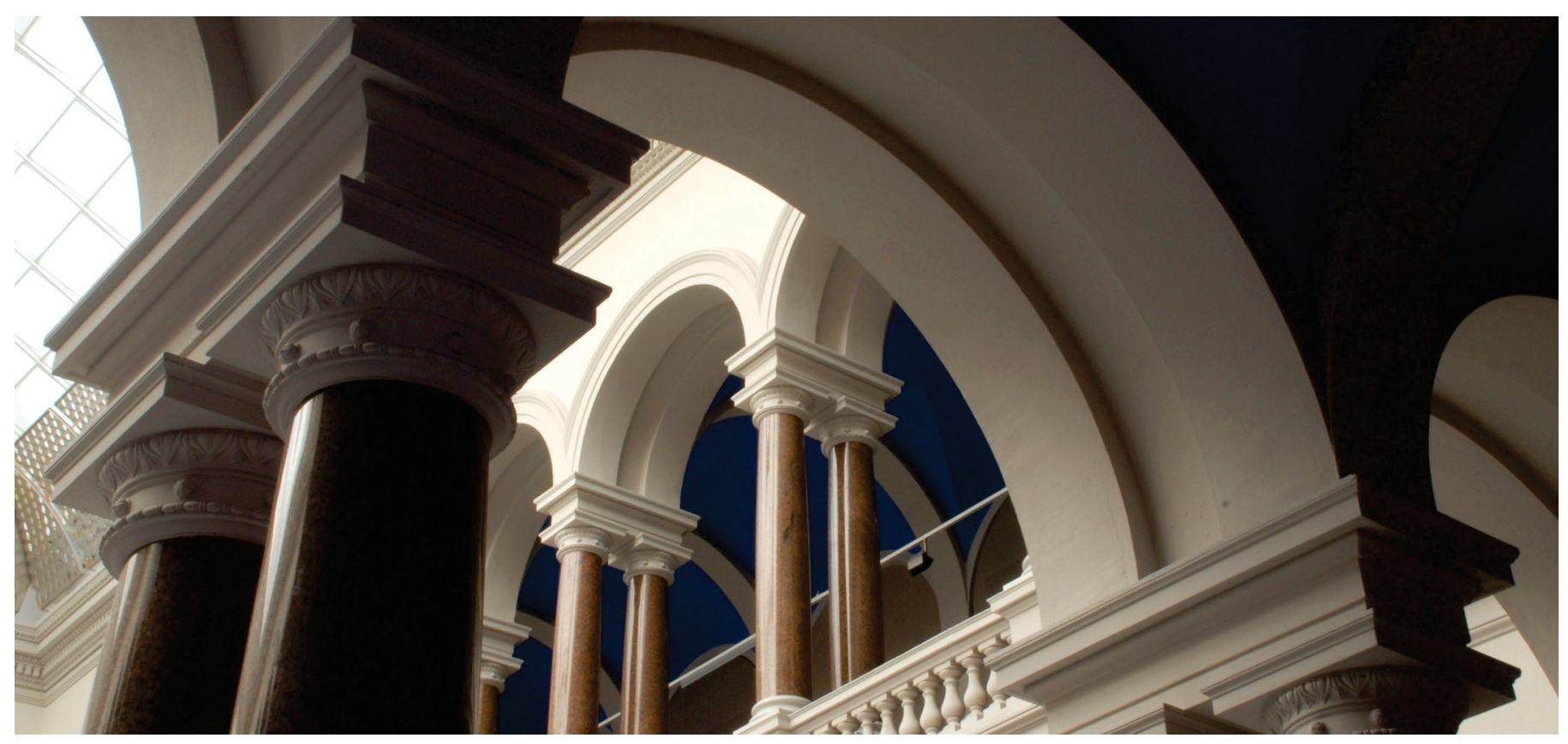

Flach, J. M., Feufel, M. A., Reynolds, P. L., Parker, S. H., \& Kellogg, K. M. (2017). Decisionmaking in practice: The dynamics of muddling through. Applied Ergonomics, 63, 133-141.

https://doi.org/10.1016/j.apergo.2017.03.017 


\title{
Decisionmaking in practice: The dynamics of muddling through
}

Submission Titel: Beyond Decisionmaking: The Dynamics of Muddling Through

\begin{abstract}
An alternative to conventional models of decisionmaking is presented. In contrast to models that treat decisionmaking as an open-loop, independent choice, this article suggests that in practice decisionmaking is more typically a closed-loop, dynamic, problem solving process. The article suggests five important distinctions between the processes assumed by conventional models and the reality of practical decisionmaking. It is suggested that the logic of abduction in the form of an adaptive, muddling through process is more consistent with the realities of practice in domains such as healthcare. The practical implication is that the design goal should not be to improve consistency with normative models of rationality, but to tune the representations guiding the muddling process to increase functional perspicacity.
\end{abstract}

KEYWORDS: Abduction, Decisionmaking, Judgment, Heuristic, Adaptive Control 


\section{Beyond Decisionmaking: The Dynamics of Muddling Through}

\section{Introduction}

When Gary Klein began interviewing firefighters in the early phases of his explorations of decisionmaking in complex work domains, he ran into an unexpected problem. A common response from the firefighters he interviewed was that they didn't make decisions, they put out fires. Klein [1] writes 'to hear them describe it, they didn't really consider anything; they just acted."

Winograd and Flores [2] made a very similar point in discussing decisionmaking in relation to management. They suggested that "instead of talking about 'decisions' or 'problems' we can talk about 'situations of irresolution,' in which we sense conflict about an answer to the question 'What needs to be done?"' (p.147).

In some cases, the answer to the question "What needs to be done?" will be obvious to practitioners (e.g., firefighters, clinical physicians, military commanders, process control operators). In these cases, their experiences will be much like that of the firefighters - they recognize a familiar situation and they skillfully do the routine activities necessary to get the work done (e.g., follow standard procedures). In other cases, the answers may not be so obvious. In these cases, it will be necessary for the practitioners to diagnose the problem through a trial and error process. It is the diagnosis process that many people have in mind when they think about practical decisionmaking. However, diagnosis is happening in both cases. In the familiar case it feels more 'intuitive,' whereas in the unfamiliar case it feels more 'deliberative.' Do these represent two distinct cognitive processes or do these cases represent a single muddling process, adapting to two distinct situations? 
In observing skilled performance in complex domains, we have begun to wonder whether the isolated choices and logical puzzles that provide the basis for much of the laboratory research on 'decisionmaking,' are representative of the choices made in complex work domains. Thus, we have become skeptical about whether the theories of human performance based on and motivating this type of laboratory research will have much value for improving or supporting performance in these domains. Table 1 contrasts 5 misconceptions about decisionmaking that are associated with classical models with the reality experienced by people working in complex domains. In discussing the contrasts, we will use examples from research in the healthcare domain to ground our hypotheses.

Table 1. Five misconceptions about cognition in complex work domains.

\begin{tabular}{|l|l|l|}
\hline & \multicolumn{1}{|c|}{ Misconceptions } & \multicolumn{1}{|c|}{ Reality } \\
\hline $\mathbf{1}$ & $\begin{array}{l}\text { Decisions are independent events. } \\
\mathbf{2}\end{array}$ & $\begin{array}{l}\text { A decision stage of information processing can be } \\
\text { isolated as an independent open-loop process. }\end{array}$ \\
\hline $\mathbf{3}$ & $\begin{array}{l}\text { There are two independent modes of decisionmaking } \\
\text { (System 1 or Intuitive and System 2 or Analytical) } \\
\text { process. }\end{array}$ & $\begin{array}{l}\text { Decisions are intimate components in a closed- } \\
\text { loop, perception-action dynamic. }\end{array}$ \\
\hline $\mathbf{4}$ & $\begin{array}{l}\text { Heuristics are biases that result from hard constraints on } \\
\text { in decisionmaking are emergent properties of a } \\
\text { single dynamic process. }\end{array}$ & $\begin{array}{l}\text { Heuristics reflect tricks of the trade in which } \\
\text { humans leverage problem constraints in intelligent } \\
\text { ways. }\end{array}$ \\
\hline $\mathbf{5}$ & $\begin{array}{l}\text { The 'muddling through' processes observed in dealing } \\
\text { with complex problems should be corrected so that } \\
\text { people conform better with normative prescriptions from } \\
\text { mathematical models of rationality. }\end{array}$ & $\begin{array}{l}\text { The 'muddling through' processes observed in } \\
\text { dealing with complex problems are an intelligent } \\
\text { response to complexity and this muddling process } \\
\text { should be encouraged and supported. }\end{array}$ \\
\hline
\end{tabular}

The point of this article is to draw attention to the distinct aspects of skill and expertise in complex work domains that are not well represented in traditionally accepted reductionist experimental approaches and the associated theories of human rationality and decisionmaking. In essence, we are challenging the external validity of the conventional decision literature with 
respect to generalizing to practical situations [3]. The practical reality that we describe has been recognized by many others - who have used various terms to describe it:

- Abduction (Peirce) [4]

- Assimilation/Accommodation (Piaget) [5]

- $\quad$ Productive Thinking (Dunker, Wertheimer) [6.7]

- Muddling or Incrementalism (Linblum) $[8,9]$

- Adaptive Control (Flach) [10, 11]

- Recognition-Primed Decision Making (Klein) [12]

- Ecological Rationality (Gigerenzer) [13, 14]

- Situated Cognition (Hutchins, Suchman) $[15,16]$

Despite the many surface differences in language and context across these constructs, we believe that there are important common intuitions about the dynamics of human decisionmaking and problems solving. We hope this discussion will help to illustrate and amplify those common intuitions and the potential implications for designing interfaces and training programs to enhance human performance in complex work domains.

\section{Decisions are not independent events}

An abnormal arterial blood gas may require up to ten separate decisions to determine the cause(s) of the abnormality. If the physician sees an average of three patients an hour, the total number of these individual decisions on each patient requiring a significant workup may go into the hundreds, and the total for a shift will be in the thousands. (p. 1185). 
As Croskerry [17] observes, physicians must typically make many choices in the course of a work shift. However, in contrast with decision tasks used in much of the laboratory research, these choices are not isolated 'separate' or 'individual decisions.' Rather, these choices are components in a dynamic process to make sense of the situation and to resolve it. Thus, the abnormal arterial blood gas is a situation that requires resolution. Achieving resolution may require multiple actions, including tests to confirm or rule out hypotheses, treatments to resolve or stabilize underlying issues, and/or referrals to appropriate specialists to manage further treatment. However, these multiple actions are not 'independent' events or choices. Rather, they are integral components of a search to find a satisfactory resolution to the situation of the abnormal blood gas.

Research by Feufel [18] suggests that in emergency medicine the resolution process is often jointly guided by two heuristics: 1) common thing; and 2) worst thing. The 'common thing' heuristic will focus on identifying the most common (most probable or most likely) reasons for the abnormal situation and on choosing the standard or typical procedures for resolving such situations. In this case, tests will typically be chosen in order to provide evidence to confirm that the situation is a 'common thing' and that the standard procedures are appropriate.

However, at the same time that the emergency physicians are trying to confirm that the situation is 'common,' they may simultaneously be considering possible hidden dangers (worst things). In fact, eliminating potential worst things may be the top priority in the case of emergency medicine. In resolving the 'worst thing' hypothesis, the physicians are more likely to be seeking disconfirming evidence, in order to rule out lower-probability, but dangerous possibilities that could lead to dire consequences if missed. For example, an EKG might be 
ordered to rule out an acute myocardial infarction in an older woman presenting with nausea and vomiting.

The key point here is that the choices that physicians make (e.g., to order a particular test, to initiate a specific treatment, or to make a specific referral) are not independent decisions, rather they are components in a dynamic process of generating and testing hypotheses and acting based on an evolving assessment of the situation. In emergency medicine this resolution process will often be guided by competing hypotheses about potential "common" and "worst" things.

Figure 1 illustrates two distinct perspectives on decisionmaking. Figure 1A shows the conventional model where the decision process is viewed as an open-loop, inferential process consistent with models of deduction and/or induction. Figure 1B shows a closed-loop dynamic process consistent with Peirce's abduction [4] and Sowa's Cognitive Cycle [19]. Abduction is a pragmatic approach to evaluating hypotheses (or beliefs) relative to the practical consequences of acting on those hypotheses. Beliefs that lead to actions that have satisfying results are retained. Otherwise, they are revised to provide a reasonable alternative that is consistent with the resulting feedback. This is a kind of learning by doing and is consistent with Piaget's [5] dynamics of assimilation (generalizing from past experiences or schema to generate hypotheses and guide action) and accommodation (using feedback to revise schemas toward improved fitness with the current situation). In the abduction process, hypotheses direct both treatments and tests, and in turn, the hypotheses or underlying beliefs are retained or revised as a result of the feedback in terms of unexpected results (surprises) or deviations from treatment expectations and goals (errors). A central premise of this article is that the closed- 
loop dynamic of abduction is a more appropriate model for the cognitive processes involved in diagnosing and treating patients in a medical context such as the emergency department.

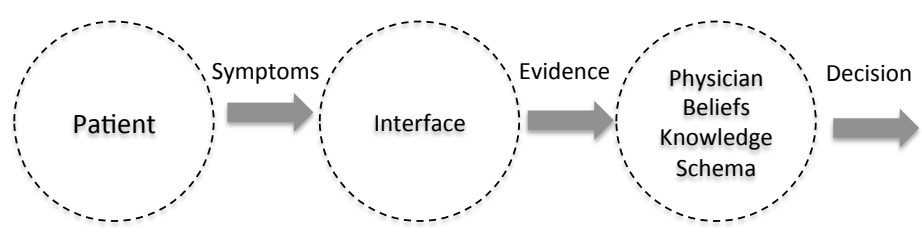

A. Open-loop induction/deduction.

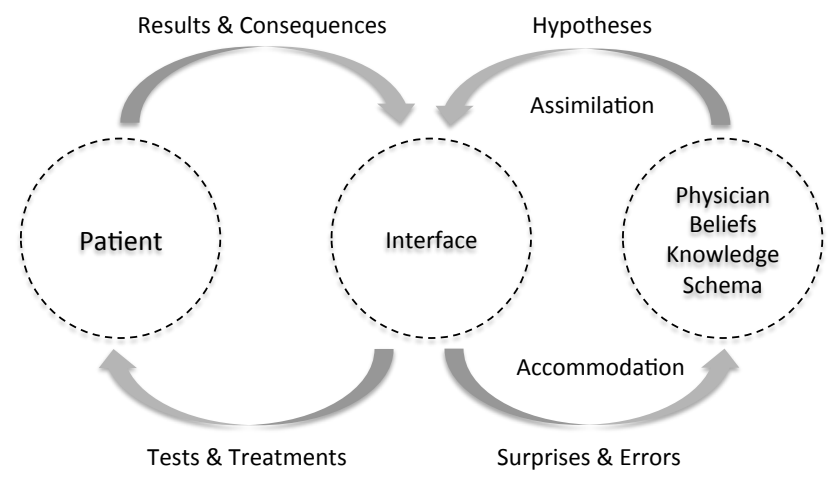

B. Closed-loop abduction.

Figure 1. This illustrates the difference between an open-loop, inferential logic and a closedloop, abduction process in which hypotheses guide actions that have consequences that feed back and, in turn, shape beliefs and subsequent hypotheses. See Flach \& Voorhorst for more detailed description of the abduction dynamic [20].

\section{Decisions cannot be isolated from the perception-action dynamic}

De Groot finally succeeded in separating strong from weak players by using perceptual tests involving the reproduction of chess positions after brief exposure to them (3-7 seconds). The grandmaster was able to reproduce the positions perfectly, and performance degraded appreciably with decrease in chess ability. De Groot was led to propose that perceptual abilities and organization were an important factor in very good play (emphasis added). 
As the above quote suggests, quality choices of expert chess players often involve what Dreyfus describes as a perceptual process of 'zeroing-in' on a promising situation. Dreyfus notes that "only after the player has zeroed in on an area does he begin to count-out, to test, what he can do from there" [22]. He continues, observing that "the human player... is not aware of having explicitly excluded from consideration any of the hundreds of possibilities that would have had to have been enumerated in order to arrive at a particular relevant area of the board by counting out" [22]. In generalizing this to emergency medicine, in applying the 'common thing' and/or 'worst thing' heuristics the physician is delimiting the space of possibilities that will be considered. Thus, with experience, a skilled clinician will quickly zeroin on or recognize a few of the most likely possibilities associated with a particular case.

Winograd and Flores [2] make a similar observation about management decisions, noting that in the process of formulating the problem there is a "pre-orientation of possibilities" that simultaneously reveals some possible actions while concealing others. As noted earlier, Klein's Recognition-Primed Decision (RPD) model also reflects the observation that perception (or recognition) of the situation plays a critical role in expert decisionmaking [12]. He noted that the choices of the experienced fire commanders rarely involved comparing alternatives, rather they involved assessing the situation and testing hypotheses. Klein observed that in highrisk situations, these hypotheses were often tested through 'mental simulations,' which involved imagining a course of action and the potential consequences. This process seems to be analogous to the "progressive deepening" process of sequentially evaluating and accepting or rejecting alternatives described by Gestalt psychologists [6,7]. This process is self-terminating upon discovering the first acceptable (or satisfying) hypothesis. Ultimately, the hypotheses will be tested by acting on them. In domains such as medicine, where windows of opportunity for 
successful action may be closing rapidly - there may be limited time for extensive mental simulations and decisive action may supersede the requirement for certainty. .

In contrast to these observations of decisionmaking in complex domains, laboratory research on decisionmaking has typically focused on processes associated with comparing alternatives. Participants are typically presented with a pre-determined set consisting of a few alternatives and are asked to choose the best one [23]. This allows the choice processes to be isolated from perceptual and memory processes that would normally be involved in generating alternatives. Performance of the participants is typically gauged relative to normative models for identifying the 'optimal' or 'rational' choice from among the fixed set of alternatives. Deviations from the prescriptions of the normative models are generally considered to be errors; and there is an at least implicit implication that these errors might be corrected by teaching people the normative models. However, there is little empirical evidence to support the idea that training with respect to normative models of rationality improves performance in complex domains $[24,25]$.

In addition to isolating the choice process from the perceptual aspects of problem formulation, the laboratory tasks typically used to evaluate decisionmaking involve bounded problems, where the set of alternatives is fixed and the number of variables to consider is typically well within-the capacity of working memory. However, in domains such as healthcare, the problems are typically dynamic. As Montgomery noted, potentially "useful information is available in overwhelming quantities, and physicians have the daily task of sorting through it and deciding how some part applies to an individual patient in a given circumstance" [26]. It often takes time to access relevant information and in some cases it is necessary to act quickly, before all the potentially relevant information is available in order for the actions to be effective 
in preventing an evolving dangerous situation. For example, time is critical in treating sepsis or septic shock in both the ED and Neonatal Intensive Care [27, 28]. Research suggests that delays in the administration of antibiotics can result in significantly increased mortality rates [29].

Research by Damasio [30, 31] highlights a potential problem with purely 'rational' approaches to decisionmaking - these rational processes can get caught in a paralysis of analysis, where actions are delayed by excessive deliberations. Unlike many of the heuristics used by experts, normative approaches to rationality don't have intrinsic 'stop rules' for terminating the evaluation process and acting. In many dynamic situations a bias toward action can be essential to resolving problems. Damasio's work suggests that emotional components may play an important role in tuning the criteria for intuitively triggering action in dynamic situations (for similar arguments see Simon [32]).

The key point here is that the process of comparing options that is typically the focus of laboratory research on decisionmaking seems to account for very little of the variance that separates experts from novices with respect to quality of practice in a domain such as medicine. Rather, it seems that the perceptual processes associated with formulating the problem, generating hypotheses, and triggering actions are critical factors for effective performance in complex work domains. For example, with respect to the common and worst thing heuristics, this would suggest that a key distinction between expert and novice physicians would be the sets of alternative 'common' and 'worst' things that they generate and the relative emphasis (weighting) that they give to the different alternatives. Thus, in isolating the 'choice' processing from other components of the perception-action dynamic, it is likely that researchers 
have broken the cognitive dynamic in a way that undermines its relevance for the design of training protocols or interfaces to improve the quality of medical practice.

The distinction between knowledge and the situated skill of muddling is implicitly recognized within accreditation requirements for post-graduate physician training programs that lead to specialty board certification. All such programs include both exambased assessment biased towards knowledge (open-loop, rule-based logic) and mentoring-based assessment whereby expert faculty guide and judge the degree to which novice trainees develop effective muddling skills. Trainees require satisfactory performance in both domains in order to progress. This is equally true for those specialties with a predominantly cognitive skillset, such as internal medicine, as for surgical specialties, which have a perhaps more obvious need for practical assessment.

\section{The Muddling Process is an integrated adaptive control system, rather than two distinct processing paths.}

In attempting to account for the qualitative differences between the behavior of domain experts such as the fire ground commanders interviewed by Klein and the normative expectations that shape much of the classical laboratory research, some have proposed that there are dual processes or separate systems underlying choice behaviors [23, 33, 34]. Choices that are made automatically, under high time pressure, with little apparent deliberation, are called intuitive or System 1 decisions. This system typically relies on heuristics that put minimal demands on cognitive resources (e.g., working memory) and that allow quick decisions/actions. However, this path often involves systematic deviations from normative prescriptions for integrating the data. 
Choices that involve more extended time allowing more thorough deliberations are called analytical or System 2 decisions. This system tends to be slow and it puts heavy demands on cognitive resources. However, this system typically conforms more closely to the normative prescriptions for integration of the evidence available. The operation of this system is what most people typically have in mind when they talk about decisionmaking.

While System 1 is often associated with skill or expertise, there is at least an implicit assumption that with respect to rationality this system is more vulnerable than System 2. For example, Croskerry claims that "robust decision making is more analytical than intuitive. It adopts a systematic approach to remove uncertainty within the resources available to make safe and effective decisions" [35]. Despite its weakness, employing System 1 is often necessary or preferred due to constraints on time (e.g., need for quick action) or available cognitive resources (e.g., multi-tasking). A critical question with respect to the quality of decisionmaking is how to resolve potential conflicts between these two systems. For example, are there situations when a clinician should 'slow down' (employ the analytic system) in order to avoid potential errors associated with the intuitive system [36]?

Although Systems 1 and 2 are often discussed as distinct systems due to the qualitative differences, we think that it is misleading to infer that the qualitatively different experiences associated with 'intuitive' and 'deliberative' situations reflect distinct, independent cognitive processes. In practice, the coupling of these two processes will be critical in determining the quality of performance as Moulton, Reegher, Mylopoulos, and MacRae [36] observe:

Although gaining an understanding of both the cognitively effortful, analytic processes and the automatic, nonanalytic resources of expertise is important it might be argued ... that the true hallmark of expertise may be the effective 
interfacing between these two modes of processing. When a clinical presentation is atypical, a postoperative patient goes off course, an unusual reaction occurs from medication, or an anatomical anomaly is confronted, will the clinician, in automatic mode, take heed and recognize the intricacies and complexities of the case and leave automatic mode, or will the clinician plow through, oblivious to its uniqueness and unaware of its consequences?

Figure 2 illustrates abduction as a kind of adaptive control system where performance is a function of two intimately coupled loops. The lower or inner loop reflects Piaget's assimilation process. This loop provides a direct coupling of perception and action, such that action is directly modulated by feedback (i.e., observations of the consequences of prior actions). The feedback in this loop reflects deviations from a desired state (e.g., certainty about condition and/or resolution of health problems) and the actions (e.g., tests and/or treatments) are guided by hypotheses and heuristics (or schema) with the ultimate intention to reduce 'errors' relative to this desired state.

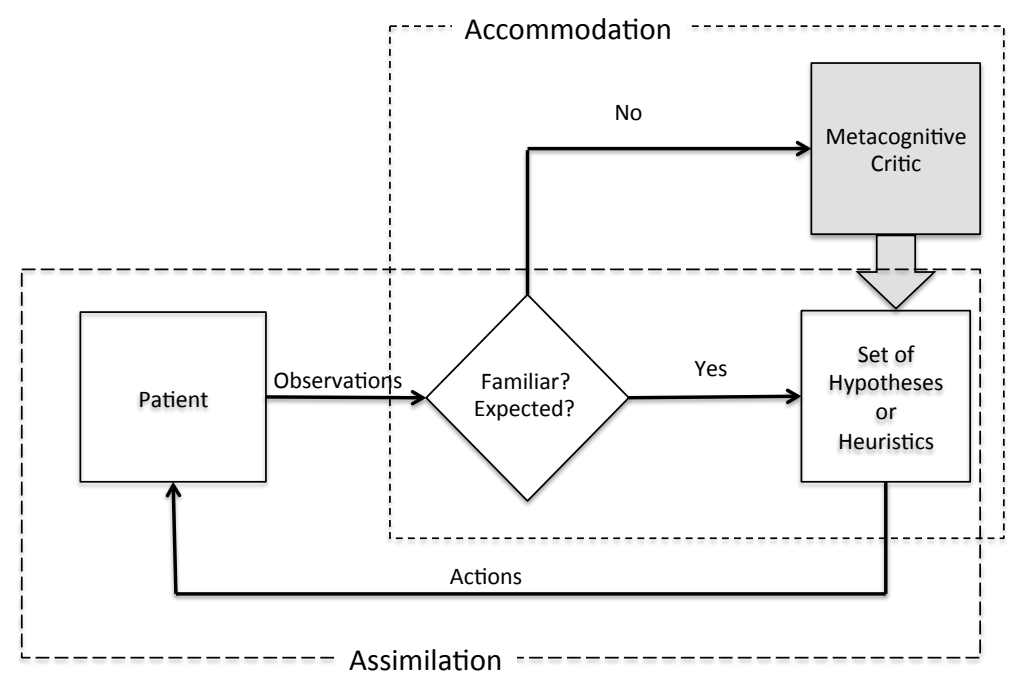

Figure 2. The abductive or muddling process involves two coupled loops in the form of an adaptive control system. 
The upper or outer loop in Figure 2 reflects Piaget's accommodation process. This loop functions as a monitor/critic/supervisor of the inner loop. In essence, this loop monitors the inner loop activity to detect anomalies or surprises. When anomalies are detected, the outer loop modifies the inner loop, with the goal to bring the inner loop process back in line with goals and expectations. A surprise might typically indicate that the hypothesis set guiding inner loop actions is wrong or incomplete. Thus, modifications to the inner loop might typically involve changes to the assumptions (e.g., heuristics and/or hypotheses) that are directing actions in the inner loop (e.g. switching emphasis from common to worst thing or adding alternatives to the lists of things being considered).

There are two important implications of the adaptive control model in Figure 2 relative to dual process theories of decisionmaking. First, the two loops in Figure 2 are always working together as a single unified process. That is, there is no sense in which individual loops can be turned on or off. However, it will be true that when no anomalies are detected the process in Figure 2 will be experienced as a simple control process - a process of just doing the job, guided by feedback. In this case, the outer loop will be in the background and there is likely to be little conscious experience of deliberation or uncertainty. However, when anomalies are detected - either as a conscious recognition of surprise or as a vague feeling that things are not going as expected - then the activity of the outer loop to evaluate and modify the set of potential hypotheses is more likely to be part of the conscious experience. The key point is that the monitoring process is continuously working in the background, even when it is not consciously experienced. As Moulton, Regehr, Mylopoulus and MacRae note "at any given moment in time, attention needs to be allocated to monitoring the environment for unexpected and unanticipated cues, as well as for assessing results of actions already taken" [36]. 
The second important implication of the model in Figure 2 is that the coordination of the two loops is largely a function of perception/attention, NOT a function of rationality or conscious choice. That is, activity of the outer loop is contingent on detecting anomalies relative to expectations about the inner loop. In other words, the decision to slow down is also recognition-primed. The coordination between the two loops is a problem of situation awareness. As Moulton Regehr, Mylopoulos and MacRae [36] note, errors are often not due to failures of rationality, but to incomplete assessments of the situation:

Often, the decision made in a critical situation was the correct decision given the parameters that the individual was considering, but the parameters themselves were wrong or incomplete because of failures of situation awareness. Poor situation awareness has also been considered a primary causal factor for error in many diverse domains, including medical dispatch, medical diagnosis and anesthesia.

In sum, the main point here is that although the experiences of decision makers can vary on a continuum from feeling like a well tuned control process (e.g., just doing the job) to a more deliberate search to make sense of and manage an uncertain situation, the underlying perception-action process is a single multi-loop muddling process, rather than a collection of distinct or independent processes. The qualitative differences in experience do not reflect distinct internal cognitive processes or mechanisms, but rather adaptive responses to distinct situations (e.g., familiar versus unfamiliar). 


\section{Heuristics: Biases or Tricks of the Trade}

It is generally recognized that heuristics are essential to skilled performance. In essence, heuristics are the tricks of the trade that allow experts to quickly recognize a situation in order to select or 'prime' the right action from among a myriad of choices. However, these tricks of the trade are bounded or situated. That is, heuristics are a local form of rationality that are only valid in certain situations, as opposed to many of the normative models underlying classical experimental approaches to decisionmaking that are considered to be universally valid, or context independent [13].

In the classical approach, much attention is paid to the limitations of heuristics. So much so that these are often seen as synonymous with bias. Further, they are viewed as significant sources of error in human decisionmaking that need to be corrected through training [23]. The reliance on heuristics is treated as a factor that undermines the quality of System 1 and makes it the weaker of the two distinct modes associated with the classical model. This leads to the conclusion that people should be trained to not put too much trust in System 1 and to defer to System 2 whenever time and circumstances allow. The rub, however, is how to recognize when time and circumstances allow. Consider Croskerry’s observation about heuristics (or Cognitive Dispositions to Respond - CDR) in medicine:

It should be emphasized that the CDR, itself, is neither a failing nor an error; it is only when CDRs result in adverse outcomes that they become cognitive errors. Interestingly, virtually every cognitive error is judged preventable in hindsight. [17]

While it may be easy to recognize that a heuristic has been over extended or over generalized in hindsight (i.e., after an unfortunate result), expert performance requires the 
ability to detect the bounds of the heuristic in foresight. This type of sensitivity to the contextual limitations of different heuristics may be in part what pilots call 'situation awareness' and physicians commonly refer to as 'good judgment' [37]. In the adaptive control model, this is the function of the outer metacognitive loop, to see the bigger picture and to detect when there are anomalies that indicate that the heuristics guiding the activities no longer fit the current situation.

In the context of the adaptive control model, heuristics are considered to be an ecologically rational basis for linking perception and action in the inner control loop [13, 14, 20]. In other words, heuristics are Smart Mechanisms that cleverly use local constraints to simplify complex problems and to trigger skilled action [38]. A primary function of the outer loop is to detect when the bounds limiting the applicability of a heuristic are crossed (i.e., detect anomalies relative to expectations) in order to adjust the logic guiding behavior in the inner loop (e.g., change the hypothesis set or switch heuristics).

There are two important points to consider when evaluating heuristics relative to normative prescriptions for decisionmaking. First, it is important to realize that normative prescriptions are also pragmatically 'bounded' forms of rationality. In particular, the normative approaches are bounded by the quality of data that they are applied to $[13,14]$. For the most part, the normative prescriptions apply to the 'counting-out' aspect of the decision process (i.e., evaluating or comparing alternatives). However, the data available to the counting-out process is a function of the prior 'zeroing-in' process. Even if the comparison or evaluation process conforms exactly with normative prescriptions, the decision may be flawed if the correct diagnosis is not in the set of alternatives being considered or if the data about the patient 
state are noisy/erroneous or incomplete. Practically, there is no 'unbounded' rationality - so the key is to choose the process that fits best with the situated constraints.

The second point to consider when comparing heuristics to normative prescriptions has to do with the dynamic or temporal constraints in domains such as medicine that have been eluded to earlier (e.g., the need for quick action in the case of sepsis). The practical heuristics that guide expert behavior typically have the dynamic constraints baked in. That is, these heuristics are often in the form of recipes for action - if you suspect sepsis, administer antibiotics at the earliest opportunity. Normative models that were designed to be universal are rarely grounded in the pragmatic dynamics of specific domains such as medicine. Thus, they lack the 'stop-rules' necessary to prevent interminable analyses that may ultimately find the right answer, but that may be too late for the actions to be effective. For example, waiting for a suspicion of sepsis to be confirmed by lab reports before administering antibiotics.

Finally, in making judgments about the quality of decision processes that result in bad outcomes, it is important to realize that information that may be salient in hindsight, may not have been salient at the time decisions were made. It is also important to realize that it may be difficult to fully appreciate the dynamic constraints (e.g., sense of urgency) being experienced by a physician from the perspective of hindsight. Interventions to improve decisionmaking and to prevent future bad outcomes that are based on such hindsight biases are not likely to be effective in improving the healthcare system [39].

\section{Muddling Through: Something to be corrected or supported?}

Twenty years after describing public policy making as an incremental, muddling through process $[8,9]$, Lindblom reviewed the literature and found that there was general 
consensus that his description of 'muddling' was an accurate account of how public policy making typically happened [e.g., see Weick's [40] discussion of sensemaking in organizations . However, there remained significant disagreement about how public policy making 'ought' to happen. He observed that many people believed that the process could be improved (i.e., fixed) by making it conform more closely to the normative models. In contrast, Lindblom believed that the muddling through process was actually a very effective process for solving complex problems. In other words, he believed that the muddling through process was a valid, ecologically rational approach to making public policy. He suggested that efforts to improve policy making should focus on supporting or tuning the muddling process, rather than on supplanting it in favor of more normatively rational processes.

Lindblom's hypotheses about public policy making and Weick's descriptions of sensemaking are consistent with the themes of this paper. Thus, we would like to consider two implications for improving the quality of practice. The first implication is that decisions are ultimately made by organizations, not individuals. For example, Hutchins makes a strong case that, for ship control, the navigation team along with their tools is the cognitive and computational system [15]. In the medical context we suggest that treatment decisions are ultimately made by the Emergency Department (ED), not by an isolated individual physician. To be more specific, we suggest that both the assimilation and accommodation functions illustrated in Figure 2 are distributed over people and technology in the ED. Typically there is a supervisory hierarchy in the ED with senior physicians monitoring the activity of junior physicians. Thus, the senior physicians play an important role with respect to the metacognitive critic function (upper loop), monitoring for anomalies and helping to ensure that the heuristics guiding the activities of the junior physicians (lower loop) are appropriate to the situations. In a 
high functioning ED, this sharing of responsibility to alert colleagues to potential anomalies that might reflect the bounds of a dominant heuristic or typical situation is likely to go beyond the formal hierarchies, so that every one in the ED feels empowered and responsible to voice concerns with respect to the activities of their colleagues.

This suggests that the attunement of the muddling process (e.g., the ability to detect anomalies or sensitivity to the local limits of a heuristic) will depend on communications within organizations. Recent research on group problem solving supports this [41]. This research found that the quality of group problem solving depended critically on listening and turn taking within the group. The research showed that indexes of social sensitivity were more important to the quality of group problem solving than were indexes of intelligence. This has particularly important implications for the medical field, where Leape and colleagues have suggested that the insensitivity of physicians (e.g., lack of respect for colleagues) is a major contributing factor to medical error $[42,43]$. Feufel also found the ability to establish rapport and to listen to patients was a critical skill for ED physicians [18].

Thus, an important implication of the distributed nature of cognition in complex systems like the ED is that 'non-technical' skills (e.g., social sensitivity, leadership, team coordination) may be as important to the ultimate quality of performance and safety as are technical skills (e.g., knowledge, analytical reasoning ability) [44, 45]. This suggests that increasing emphasis on attributes such as social sensitivity in the selection and training of medical personnel may lead to significant improvements in the quality of performance. Of course, having smart people in the organization is valuable, but an organization that functions well as a team (e.g., based on mutual respect) has the potential to be even smarter than any of its individual members. 
A second dimension to consider relative to incremental, muddling through processes is associated with the construct of essential friction [46]. In an organization, checks and balances (e.g., the requirement to get approval from the attending physician before acting; or the second guessing of a colleague) can sometimes be seen as friction. From the perspective of efficiency, these checks can be seen as wasted time or energy. But in an uncertain environment, this friction may be an essential part of the metacognitive process, helping to ensure that anomalies are detected and that the local limitations of heuristics are respected; and thus, reducing the probability that the system will plow ahead following a heuristic that is not well fit to an exceptional situation. We suggest that this friction can be a more practically valid check on the limitations of heuristics, than education with respect to formal logic.

Note that this might seem somewhat at odds with the discussion above that suggests that one of the values of heuristics is that they are recipes for action and they help to protect the system against a paralysis of analysis. However, this illustrates an emergent property of all closed-loop, adaptive systems. Stability in these systems depends on a delicate 'speed-accuracy' balance. These systems can fail either because they are too sluggish in acting to correct problems (e.g., paralysis of analysis or gain too low), or because they act too quickly and end up chasing noise rather than signal (e.g., misdiagnosing the problem and treating the wrong thing or gain too high). It is the ability to find and maintain the right balance that distinguishes high reliability organizations.

The question of the nature and appropriate level of friction is particularly timely for medicine with the increasing development and use of technologies, such as Electronic Health Record (EHR) systems. Such systems are often motivated by opportunities to increase efficiency. However, Rochlin [47] cautions that a system that makes it easier to do the right 
thing, may also make it easier to do the wrong thing. In designing and implementing EHRs, it will be important to consider whether important checks and balances are being by-passed, and also to consider how the current systems might provide the opportunity for additional friction (checks and balances) that may increase system reliability [48, 49].

\section{Summary and Conclusions}

Consistent with Lindblom's observations about the messy, muddling (but effective) nature of public policy making, there is growing consensus in the applied cognitive science literature about the opportunistic or situated nature of decisionmaking and problem solving in complex domains. In these contexts, experts tend to rely heavily on heuristics or rules of thumb that have worked consistently in the past, because they have been tuned over time to the functional constraints of the work. It is also fairly evident that failures are often associated with over generalizing these heuristics in exceptional situations where they don't fit. The point of contention, reflected in the contrasts in Table 1, are about the most effective ways for improving performance (i.e., reducing the over generalizations and failures).

The classical approach tends to focus on deviations between the heuristics and more context-free, analytical approaches to rationality. Advocates of this approach tend to attribute these deviations to limitations in human information processing capacity (e.g., limited working memory). The implications for improving the process tend toward either training humans to be more aware of the limits of general heuristics relative to the logical norms; or replacing humans with automated systems that are designed to conform with the logical norms of rationality.

The alternative, muddling through approach tends to focus on the challenge of achieving the right balance between speed and accuracy in a self-organizing system [20]. This balance depends critically on the pick-up of information (i.e., perception or attunement). Is the 
organization tuned to the right information for guiding activity in the lower loop? Are appropriate checks in place for detecting the bounds of particular heuristics (specific exceptions to the rules, anomalies) to support the metacognitive critic that monitors and adjusts the logic of the inner loop (e.g., changes hypotheses or shifts heuristics)? Thus, the focus shifts from improving the internal logic or rationality to improving the pick-up of information (e.g., through improved sensors, attention/situation awareness, interface design, and communications $[50,51,52,53,54,55])$.

The dynamical systems approach also shifts focus from the limitations of individual people to the power of distributed teams. This suggests that selecting for social sensitivity and teaching people communication and teamwork skills can be very important avenues for improving systems performance. Similarly, if work is to be supported by technology, its effect on team and/or organizational performance should also be considered rather than individual level outcomes alone $[44,45,53,54]$.

The practical questions are why do failures happen and how can we reduce the potential for future failures? The classical approach focuses on how individuals 'think' and on ways to improve thinking. The alternative approach focuses on how people 'see and listen' and on ways to improve seeing and listening. To be clear, the implication of the alternative approach is not that 'thinking' is unimportant. But rather that it is not enough. For example, Asch et al. [56] found that patient outcomes were related to aspects of residency training other than the licensing exam scores. Thus, the differentiator for predicting physician skill was not knowledge as measured by the licensing exams. For the medical domain, the quality of thinking is generally quite high. However, there may be significant room for improvement with respect to 
seeing (e.g., tuning to anomalies that reflect the situated bounds of standard procedures and heuristics) and listening (e.g., respecting and communicating with colleagues and patients). An important leverage that designers have for improving performance and reducing errors for an adaptive (abduction based) muddling through rationality is the design of representations [e.g., 47, 57, 58]. This includes shaping external representations (interface design) and shaping internal representations (training system design) - to increase the salience/awareness of both the feedback relative to controlling action and the feedback relative to detecting anomalies and exceptions (e.g., the situated bounds of heuristics) to trigger a change of hypotheses or heuristics. The ultimate goal is not to make the system more logical in the classical sense, but to make it more perspicacious. 


\section{References}

1. Klein, G. Intuition at work. New York: Random House; 2003

2. Winograd, T. \& Flores, F. Understanding computers and cognition. Boston: AddisonWesley; 1987.

3. Grimes, D.A. \& Schulz, K.F. Bias and causal associations in observational research. The Lancet. 2002; 19 (Jan), 248-252.

4. Peirce, C.S. Harvard lectures on pragmatism, Collected Paper, v. 5. 1903.

5. Piaget, J. \& Inhelder, B. The psychology of the child. New York: Basic Books; 1969.

6. Duncker, K. On problem solving. Psychological Monographs. 1945; 58(5), Whole No. 270.

7. Wertheimer, M. (1959). Productive thinking. New York: Harper \& Row.

8. Lindblom, C.E. "The science of 'muddling through'." Public Administration Review. 1959; $19,79-88$.

9. Lindblom, C.E. "Still muddling, not yet through." Public Administration Review. 1979; 39, $517-526$.

10. Jagacinski, R.J. \& Flach, J.M. Control Theory for Humans: Quantitative approaches to modeling performance. Mahwah, NJ: Erlbaum, 2003.

11. Flach, J.M., Bennett, K.B., Jagacinski, R.J., Mulder, M., van Paassen, M.M. The closedloop dynamics of cognitive work. In J.D. Lee and A. Kirlik (Eds.). The Oxford Handbook of Cognitive Engineering. CH 1, (pp. 19-35) Oxford: Oxford University Press, 2013.

12. Klein, G. Naturalistic decision making: Implications for design. State of the Art Report. Wright-Patterson AFB, OH: Crew Systems Ergonomics Information Analysis Center; 1993. 
13. Gigerenzer, G., Hertwig, R., \& Pachur, T. (Eds.). Heuristics: The foundations of adaptive behavior. Oxford: Oxford University Press, 2011.

14. Todd, P.M., Gigerenzer, G. \& the ABC Research Group. Ecological Rationality. Oxford, England: Oxford University Press; 2012.

15. Hutchins, E. Cognition in the wild. Cambridge, MA: MIT Press; 1995.

16. Suchman, L. Plans and situated actions. Cambridge, UK: Cambridge University Press, 1987.

17. Croskerry, P. Achieving quality in clinical decision making: Cognitive strategies and detection bias. Acad Emergency Med. 2002; 9(11), 1184-1204.

18. Feufel, M. A. Bounded rationality in the Emergency Department [dissertation]. Dayton, Ohio: Wright State University; 2009. Available at: http://etd.ohiolink.edu/view.cgi?acc_num=wright1249241698

19. Sowa, J.F. The cognitive cycle. Proceedings of the IEEE Federated Conference on Computer Science and Information Systems; Sept 13 -16, 2015. 11-16, Lodz, Poland.

20. Flach, J.M. \& Voorhorst, F.A. What matters? Dayton, OH: Wright State University Library; 2016. http://corescholar.libraries.wright.edu/books/127/

21. Newell, A. \& Simon, H.A. An example of human chess play in the light of chess playing programs. Carnegie Institute of Technology. August, 1964, p. 14. Cited in H.L. Dreyfus. What computers still can't do. p. 104-105. Cambridge, MA: MIT Press; 1992.

22. Dreyfus, H.L. What computers still can't do. p. 102. Cambridge, MA: MIT Press; 1992.

23. Kahneman, D. Thinking, fast and slow. New York: Farrar, Straus and Giroux; 2011. 
24. Means, B., Salas, E., Crandall, B. \& Jacobs, O. Training decision makers for the real world. In G.A. Klein, J. Orsanu, R. Calderwood, \& C.E. Zambock (Eds.) Decision making in action. Models and methods. Norwood, NJ: Ablex; 1993.

25. Klein, G. Applied decision making. In P.A. Hancock (Ed.) Human performance and ergonomics. p. 87-107, San Diego, CA: Academic Press; 1999.

26. Montgomery, K. How doctors think: Clinical judgment and the practice of medicine. Oxford: Oxford University Press; 2006.

27. Crandall, B. \& Gambian, V. Guide to early sepsis assessment in the NICU. Fairborn, OH: Klein Associates; 1991.

28. Crandall, B. \& Getchell-Reiner, K. Critical decision method: A technique for eliciting concrete assessment indicators from the 'intuition' of NICU nurses. Advances in Nursing Science. 1993; 16(1), 42-51.

29. Gaieski, D.F. Mikkelsen, M.E. Band, R.A., Pines, J.M. Massone, R. Furia, F.F. Shofer, F.S. \& Goyal, M. Impact of time to antibiotics on survival in patients with severe sepsis or septic shock in whom early goal-directed therapy was initiated in the emergency department. Critical Care Medicine. 2010; 38(4), 1045-1053.

30. Damasio, A. The feeling of what happens. Orlando, FL: Harcourt; 1999.

31. Damasio, A. Decartes' error: Emotion, reason and the human brain. New York: Putnam; 1994.

32. Simon, H.A. Motivational and emotional controls of cognition. Psychological Review, 1967; 74(1), 29-39. 
33. Hammond, K.R. Naturalistic decision making from a Brunswikian viewpoint: Its past, present, and future. In G.A. Klein, J. Orasanu, R. Calderwood, and C. Zsambok (eds.) Decision making in action: Models and methods. (p. 205-227). Norwood, NJ: Ablex Publishing; 1993.

34. Evans, J. St. B. T. Hypothetical thinking: Dual processes in reasoning and judgment. Hove, East Sussex. England: Psychology Press; 2007.

35. Croskerry, P. A universal model of diagnostic reasoning. Acad Med. 2009; 84(8), 10221028. (p. 1023).

36. Moulton, C.E., Regehr, G., Mylopoulos, M. \& McRae, H.M. Slowing down when you should: A new model of expert judgment. Acad Med. 2007; 82(10), S109-S116.

37. Donnon, T., Oddone-Paolucci, E. \& Violato, C. A predictive validity study of medical judgment vignettes to assess students' noncognitive attribute: A 3-year prospective longitudinal study. Medical Teacher. 2009; 31(4), e148-3155.

DOI:10.1080/01421590802512888.

38. Runeson, S. On the possibility of 'smart' perceptual mechanisms. Scandinavian Journal of Psychology. 1977; 18(1), 172-179.

39. Dekker, S. Drift into failure. Farnam, England: Ashgate; 2011.

40. Weick, K. Sensemaking in organizations. Thousand Oaks, CA: Sage; 1995.

41. Woolley, A.W., Chabris, C.F., Pentland, A. Hashmi, N., \& Malone, T.W. Evidence for a collective intelligence factor in the performance of human groups, Science. 2010; $330(6004), 686-688$. 
Flach et al.

42. Leape, L.L., Shore, M.F. Dienstag, J.L., Mayer, R.J. Edgman-Levitan, S., Meyer, G.S. \& Healy, G.B. A culture of respect, Part 1: The nature and causes of disrespectful behavior by physicians. Acad Med. 2012a; 87(7), 845-852.

43. Leape, L.L., Shore, M.F. Dienstag, J.L., Mayer, R.J. Edgman-Levitan, S., Meyer, G.S. \& Healy, G.B. A culture of respect, Part 2: Creating a culture of respect. Acad Med. 2012b; 87(7), 853-858.

44. Flin, R. Yule, S. McKenzie, L., Patterson-Brown, S. \& Maran, N. Attitudes to teamwork and safety in the operating theatre. Surgeon. 2006; 4(3) 145-151.

45. Makary, M.A. Sexton, J.B., Freischlag, J.A., Holzmueller, C.G., Millman, E.A., Rowen, L. \& Pronovost, P.J. Operating room teamwork among physicians and nurses: Teamwork is in the eye of the beholder. Journal of the American College of Surgeons. 2006; 202(5), 746-752.

46. Åkerman, N. (Ed.) The Necessity of Friction. Boulder, CO: Westview Press; 1998.

47. Rochlin, G. Essential friction: Error-control in organizational behavior. In N. Åkerman (Ed.). The Necessity of Friction. (p. 132-163). Boulder, CO: Westview Press; 1998.

48. Feufel, M. A., Robinson, F. E., \& Shalin, V. L. (2011). The impact of medical record technologies on collaboration in emergency medicine. International Journal of Medical Informatics, 80(8), e85-95. https://doi.org/10.1016/j.ijmedinf.2010.09.008

49. McEwen,T.R., Elder,N.C. \& Flach, J.M. Creating safety in primary care practice with electronic medical records requires the consideration of system dynamics. Journal of Healthcare Engineering. 2011; 2, 87 - 96.

50. Bennett, K.B. \& Flach, J.M. Display and interface design: Subtle science, exact art. London: Taylor \& Francis; 2011. 
Flach et al.

51. McEwen, T.R., Flach, J.M., and Elder, N.C. Ecological interface for assessing cardiac disease. Proceedings of the ASME 2012 11th Biennial Conference on Engineering Systems Design and Analysis, ESDA2012, July 2-4, 2012. Nantes, France. ASME ESDA2012-82974.

52. McEwen, T., Flach, J.M. \& Elder, N. Interfaces to medical information systems: Supporting evidence-based practice. IEEE:Systems, Man, \& Cybernetics Annual Meeting. Oct 5-8, 2014; 341-346. San Diego, CA.

53. Flach, J.M., Carroll, J., Dainoff, M. \& Hamilton, I. (2015). Striving for safety:

Communicating and deciding in sociotechnical systems. Ergonomics, 58(4), 615-633.

54. Behymer, K.J. \& Flach, J.M. (2016). From autonomous systems to sociotechnical systems: Designing effective collaborations. She Ji, The Journal of Design, Economics, and Innovation, 2(2), 105-114.

55. Flach, J.M. \& Behymer, K.J. (2016). From designing to enabling effective collaborations. She Ji, The Journal of Design, Economics, and Innovation, 2(2), 119-124.

56. Asch, D.A., Nicholson, S., Srinivas, S., Herrin, J. \& Epstein, A.J. Evaluating obstetrical residency programs using patient outcomes. JAMA. 2009; 302 (12), 1277-1283.

57. Woods, D. D. 1991. The cognitive engineering of problem representations. In Humancomputer interaction and complex systems, ed. G. R. S. Weir and J. L. Alty, 169-188. London, UK: Academic Press.

58. Rasmussen, J. and Vicente, K. J. 1989. Coping with human errors through system design: Implications for ecological interface design. International Journal of Man-Machine Studies 31:517-534. 